\title{
The connection characteristics of Titanium alloy pipes in vibration environment
}

\author{
LI YIXUAN ${ }^{1}$ HE FULIN ${ }^{2}$ \\ AVIC Aircraft Strength Research Institute, Xi'an, China \\ AVIC Flight Automatic Research Institute, Xi'an, China \\ liyixuan0430@126.com, fulin.he@qq.com ,
}

\begin{abstract}
Keywords: the titanium alloy pipes, vibration environment, connection characteristics.
Abstract. In order to determine the fatigue limits of two kinds of titanium alloy pipes connected by welding and rolling, the vibration fatigue tests were carried out according to Aero-Criterion HB5277-84 which defines the test method and failure rule[1]. The test adopted the displacement of the pipes' free end measured by the laser-displacement-sensor as the controlling parameter and the first resonance frequency of specimen as the excited frequency. It can be seen in the test: the exciting force can't remain constant when the displacement of the pipe's free end is the same. Then the test was stopped and the first resonance frequency of the pipes was tested again, and it was found that the first resonance frequency has dropped, maybe more than $1 \%$. However, the pipe in this case didn't lose its performance. It can be concluded that: 1) the failure rule defined in Aero-Criterion HB5277-84 was not suitable to some engine components with connection characteristic,2) As the connection technics (welded and rolled) quality is different, the connection stiffness is also different while the pipes' structure stays the same. So the process technics should be uniformed.
\end{abstract}

\section{Introduction}

To ensure the use safety of the titanium alloy pipes belonging to a certain type of engine , according to the Aero-Criterion HB5277-84[1], the vibration fatigue test is carried out to the pipes which is connected by welding and rolling for defining the pipes' fatigue limits and providing the design basis of the engine [2].

The specimens are special for the test and the production technology of them is as same as the ones used in actually. And the boundary condition is that fixing at one end.

'The stair method' of the fixed-frequency vibration fatigue test method was adopted to assess the specimen. The sine sweep test method is used for measuring the first frequency of the specimens and the sine fixed-frequency test method is used for measuring the fatigue limits.

The basis excitation from the vibration table was adopted in this test, and the acceleration transducer was pasted in the connection point of the clamping fixture and the specimen. The strain-gauge was pasted in the place where the highest strain happened. The displacement at the free end measured by the laser-displacement-sensor was used as the control parameter, and closed-loop control method was used for conducting the fatigue test.

\section{FEM analysis of the specimen dynamic response}

The connecting characteristics of the specimen were ignored while the finite element model was built, which is referred in Fig 1.

For simulating the real forced vibration environment of the titanium alloy pipes, a sine acceleration load of Y direction was loaded on the titanium alloy pipe's root, whose value is $1 \mathrm{~g}$. The Fig 2 shows the displacement response of the free end of the pipe, from which can be obtained the first frequency is $200 \mathrm{~Hz}$. And at the first frequency, the peak-to-peak displacement of titanium alloy pipe' free end is $3 \mathrm{~mm}$, while the $1 \mathrm{~g}$ sine acceleration signal is loaded on the end.

The first frequency $200 \mathrm{~Hz}$ is obtained by FEM ignoring the connection characteristic. As the welding ones' manufacturing technique, the size of the pipe joint gets bigger and then the bending 
stiffness gets bigger. In conclusion, the first frequency of the welding pipes get bigger as well. The rolling pipes' joint tends to be unsteady, so the first frequency of the rolling ones get smaller. The analysis is consistent with the test results.

The FEM result can be a reference value to the initial load of the pre-test.

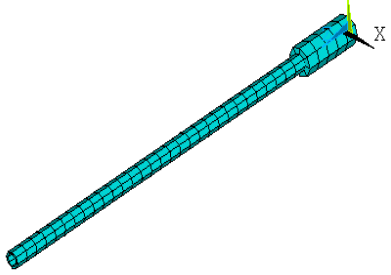

Fig 1. the finite element model of the titanium alloy pipe

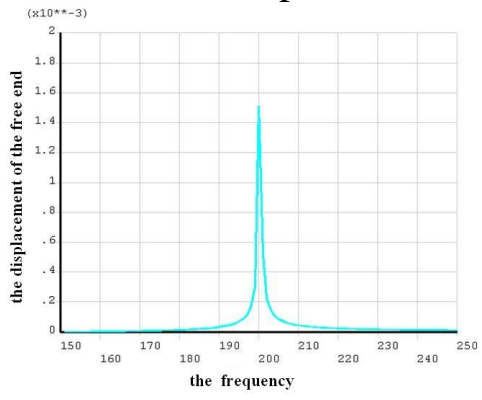

Fig 2.the displacement response of the free end under the basis excitation

\section{The connection characteristic of the welding pipes in the test}

The sine sweep test method was adopted in the test, and the sweep rate was less than 0.1 oct $/ \mathrm{min}$. Using the vibration table acceleration control mode, the pipes were swept in the estimated first resonance frequency range. Then the resonance frequency was obtained according to the response spectrum of stress and displacement.

Using the displacement of the pipes' free end measured by the laser-displacement-sensor as the control parameter, the closed-loop control method was adopted to process the fixed-frequency vibration fatigue test.

\section{The connection stiffness of the pipes decrease steadily}

The 3\# specimen's first frequency was estimated as $203.3 \mathrm{~Hz}$ by the sweep test. Then the resonance test was processed: while maintaining the displacement of the pipe's free end as $9.25 \mathrm{~mm}$, the exciting acceleration was decreasing continually from $3.3 \mathrm{~g}$ to $0.9 \mathrm{~g}$. The test was stopped and the pipe was swept again, it was found that the first frequency had dropped to $203.08 \mathrm{~Hz}$, whose change was within $1 \%$. The resonance test was restarted, and the exciting acceleration kept steady until it finished, which is referred in Fig 3. Similarly, the initial first frequency of the pipe was $203.7 \mathrm{~Hz}$, while maintaining the displacement of the pipe's free end as $9.25 \mathrm{~mm}$, the exciting acceleration maintained steady until the test finished, which is referred in Fig 3.
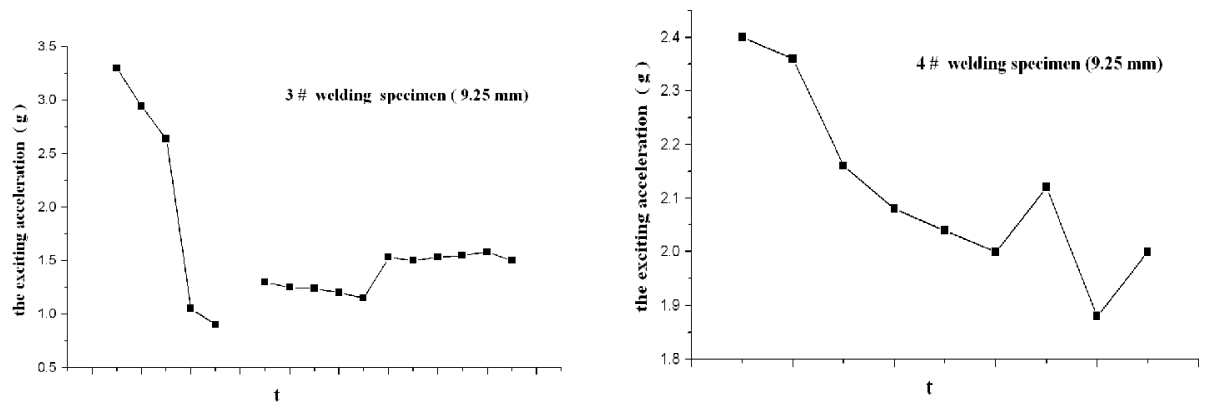

Fig 3 The connection stiffness of the pipes decrease steadily

As the connection stiffness of the specimen \#3 and 4\# decreased, the first frequency decreased. The decrease range is within 1\%, so the failure rule defined by HB5277-84 was suitable for the phenomenon.

\section{The connection stiffness of the pipes change unsteadily}

The $8 \#$ specimen's first frequency was estimated as $204.2 \mathrm{~Hz}$ by the sweep test. While maintaining the displacement of the pipe's free end as $9.25 \mathrm{~mm}$ in the resonance test, the exciting acceleration changed unsteadily. The test was stopped and the pipe was swept again, it was found that the first frequency had dropped to $203.08 \mathrm{~Hz}$, whose change was within $1 \%$. The resonance test was restarted, the exciting acceleration kept unsteady but the first frequency changed little until it finished, which is 
referred in Figure 4. Similarly, the exciting acceleration maintained unsteady until the test finished, and the first frequency increased from $203.2 \mathrm{~Hz}$ to $203.7 \mathrm{~Hz}$, which is referred in Fig 4.

\section{The connection stiffness of the pipes decrease rapidly}

The first frequency of the specimen $1 \#$ was $203 \mathrm{~Hz}$, and that of the specimen $2 \#$ was $202 \mathrm{~Hz}$. As the connection dynamic characteristic changed a lot during the resonance test, the response frequency can't keep steady. After 10 minutes lasting of the resonance test, he first frequency of them decreased rapidly (1\# decreased 2\% and 2\# decreased 5\%). Referring to HB5277-84, the specimens were regarded as damaged. However, after the checking no obvious cracks were found.

The reason may attribute to the unsteady of the connection dynamic characteristic, so the failure rule defined by HB5277-84 was not suitable for this phenomenon.
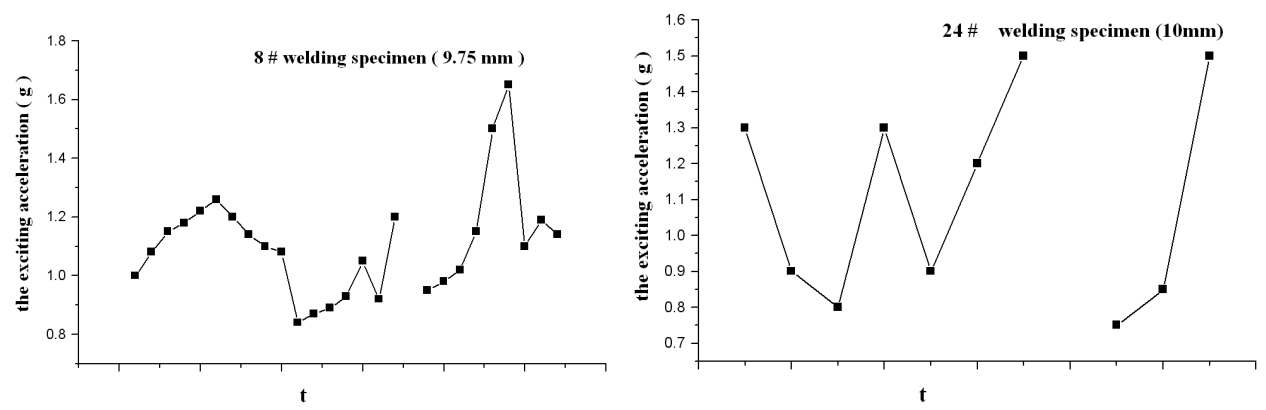

Fig 4 . The connection stiffness of the pipes decrease unsteadily

\section{The connection characteristic of the rolling pipes in the test}

The first frequency of the specimens $1 \#, 2 \#$ and $3 \#$ decreased rapidly while the resonance tests of them were processed. Due to the situation, the tests were processed using low-level exciting acceleration. However, the situation that the frequency decreased rapidly happened again.

Compared with the welding pipes, the connection characteristic of the rolling ones was more complicated and uncertain. Considering of the rolling pipes' machining features, the stepped and low-level sweep test method was adopted, and the exciting acceleration was increased gradually to explore the change law of the resonance frequency. Then the steady resonance frequency range was settled to process the fixed-frequency fatigue test. After the persistent exploring tests of 7\#,8\#,9\#,10\#,11\# and 12\#, which last about 300 hours, the peak-to-peak value $6 \mathrm{~mm}$ was determined as the initial displacement of the free end, which was the control parameter as the vibration fatigue test.

\section{The connection stiffness of the pipes increase firstly, then decrease steadily}

The 12\# specimen's first frequency was estimated as $199.5 \mathrm{~Hz}$ by the sweep test. Then the resonance test was processed: while maintaining the displacement of the pipe's free end as $6 \mathrm{~mm}$, the exciting acceleration was increasing steadily from $3.4 \mathrm{~g}$ to $4.1 \mathrm{~g}$. he test was stopped and the pipe was swept, it was found that the first frequency had increased to $199.65 \mathrm{~Hz}$. The resonance test was restarted, the phenomenon that the exciting acceleration decreased steadily happened again. The test was stopped and the pipe was swept again, the first frequency went on increasing to $199.75 \mathrm{~Hz}$.

The resonance fatigue was continuing. At this time, just like the welding pipes, the first frequency of it increased steadily, which is referred in Fig 5.

Similarly, the initial first frequency of the specimen 19 \# was $196.38 \mathrm{~Hz}$. As the exciting acceleration increased, the test was stopped, and after the specimen was swept the first frequency increased to 197.05Hz. Then the resonance fatigue was restarted and was keeping steady until the test finished, which is referred in Fig 5.

The phenomenon that the connection stiffness of the specimens 12\# and 19\# increase firstly, then decrease, would lead to the first frequency increase firstly, then decrease. All the changes are result from the connection technic of the rolling pipes. At the initial stage of test, the low-level vibration was adopted to eliminate the connection gap, which would make the connection part more homogeneous. So the stiffness of the rolling pipes increased at firstly. 
The first frequency of the rolling pipes differ from each other very much, which is referred in Table 2. It is illustrated that connection quality of the rolling pipes also differs greatly. So it can be concluded that the connection stiffness of the pipes varies a lot.
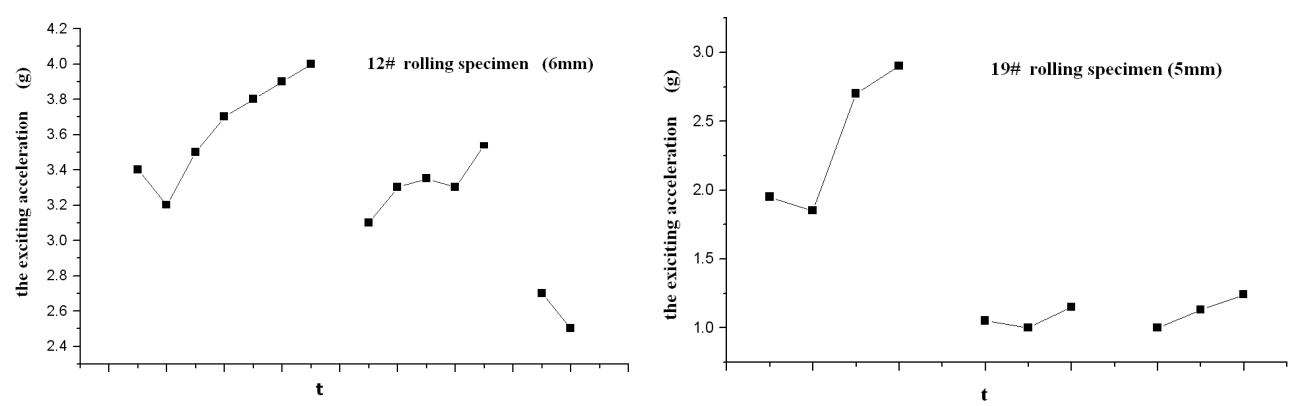

Fig 5. the connection stiffness increases firstly then decreases

\section{The connection stiffness of the pipes change unsteadily}

The $21 \#$ specimen's first frequency was estimated as $200.64 \mathrm{~Hz}$ by the sweep test. While maintaining the displacement of the pipe's free end as $5.4 \mathrm{~mm}$ in the resonance test, the exciting acceleration changed unsteadily. The test was stopped and the pipe was swept again, it was found that the first frequency had dropped to $200.5 \mathrm{~Hz}$, whose change was within $1 \%$. The resonance test was restarted, the exciting acceleration kept unsteady but the first frequency changed little until it finished, which is referred in Fig 6. Similarly, the exciting acceleration maintained unsteady until the test finished, and the first frequency increased from $199.6 \mathrm{~Hz}$ to $199.9 \mathrm{~Hz}$, which is referred in Fig 6.
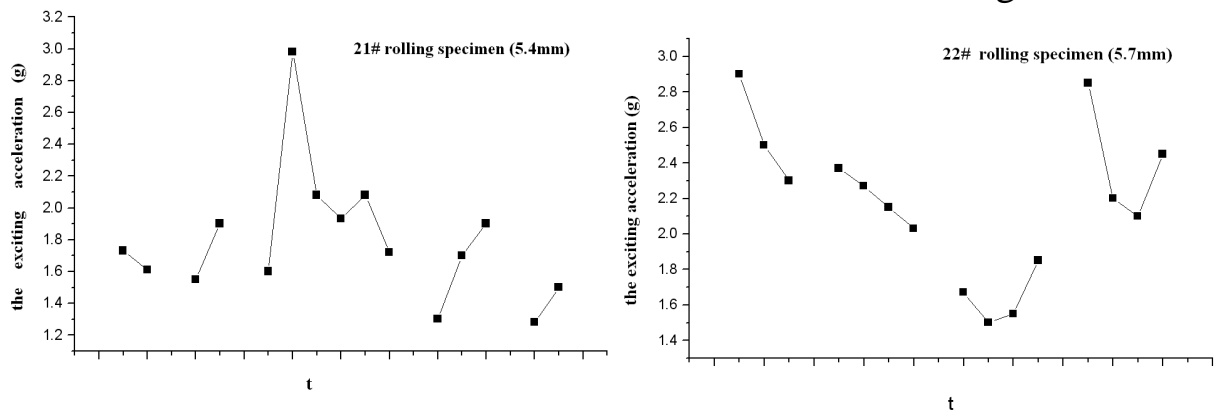

Fig 6. the connection stiffness changes unsteady

\section{Conclusions}

It was found that in the beginning of the fatigue test, the first frequency of some specimens fell very fast, however, there was no visible cracks or damage. According to the Aero-Criterion HB5277-84, the falling of the frequency up to $1 \%$ could be seen damaged. But in the test, the situation that the first frequency decreased $1 \%$ was very common, which could be attributed to the connection stiffness decreased during the test. So it is not suitable to adopt this criterion here, some failure criteria special to the connection characteristic must be discussed and adopted.

As the connection quality of the welding and rolling pipes is different, the connection stiffness is also different while the pipes' structure and size stays the same. This would lead to the first frequency of the pipes is different from each other especially the rolling ones, whose rolling technology is not uniform and the processing quality should be improved, the processing technology should be uniformed. During the fatigue test, the problem can be solved by small value sweep test as it can eliminate the connection gap of the pipes to gain a steady resonance frequency.

\section{References}

[1] AVIC, Testing method of vibration fatigue for blade and material of aero-engine[S], HB5277-1984 
[2] Shao Chuang, Qiu Ming-xing: On the vibration fatigue limit test method for metal connecting pipe $[\mathrm{J}]$ (Trans Journal of experimental mechanics, 2013, Vol.28, No.3,403 408 